\title{
Isolation and Antimicrobial Susceptibility Patterns of Klebsiella Spp. from Hund Pumped Sources Drinking Water in Kola Tembien, Central Tigray, Northern Ethiopia
}

\author{
Hadish Bekuretsion \\ Tigray Health Research Institute
}

\begin{abstract}
Klebsiella Spp. is a common environmental human and animal associated microorganism that has become a major cause of nosocomial infections worldwide. The objective of the study was to isolate Klebsiella Spp. and determine the resistance patterns of the organism. Seventy-five hand pump fitted boreholes were selected randomly. Water samples were collected aseptically. Biochemical tests were performed on colonies from macConkey agar No.3 (Oxoid.LTD) for final identification of the isolates. Isolates from all culture positive water samples were identified based on the standard cultural and morphological characteristics in couple with indole production, $\mathrm{H} 2 \mathrm{~S}$ production, gas production, citrate utilization, motility test, lysine decarboxylation, lysine deamination and carbohydrate utilization tests. Antimicrobial susceptibility test isolates were done against Amikacin, Ampicillin, Ceftriaxone, Chloramphenicol, Ciprofloxacin, Tetracycline and Gentamicin using Kirby-Bauer Disk Diffusion. Among the total of water sampled from hand pump fitted boreholes, five water $(6.6 \%)$ samples were positive for Klebsiella spp. and Among the five isolated of Klebsiella spp. from water sampled, 2 of them were resistance to Ampicillin and one was resistance to Tetracycline. This study showed that there were Klebsiella spp. from ground water which were resistance to Ampicillin and Tetracycline. Since community acquired antibacterial resistance of Klebsiella $s p p$. has a great public health importance, researchers should give attention like hospital acquired one.
\end{abstract}

Keywords: Klebsiella spp. antimicrobial resistance

DOI: $10.7176 / \mathrm{JHMN} / 59-02$

\section{Introduction}

Klebsiella Spp. common environmental human and animal associated microorganism that has become a major cause of nosocomial infections worldwide, particularly in tropical and subtropical regions, and are ubiquitous, including forest environments, vegetation soil, water, and mucosal membranes of host species (Bagley,1985).

underground water which is consider as clean and pure form of water because of the purification properties of the soil; (WHO, 2004b) however, water from these sources can be contaminated due to improper design and construction of hand pump fitted boreholes, shallowness, and proximity to toilet, Sanitary landfills, refuse dump sites, and various human activities, which can serve as source of contamination (WHO, 2013). In addition to Klebsiella, other bacteria (Pseudomonas aeroginosa, Salmonella, Mycobacteria, E. coli, Proteus, Shigella sonnei, Klebsiella, Cyanobacteria) and viruses derived from human and animal faeces also contaminate water sources from ground (WHO, 2004b).

The contribution of groundwater to the global incidence of waterborne disease cannot be assessed due to many as there are many competing transmission routes; confounding from socio-economic and behavioral factors are typically high (pandey et al., 2014). However, there were reports from USA and UK which had some indications of the role of groundwater in the infectious diarrhoeal disease (Prüss and Havelaar, 2001). The use of contaminated, untreated or poorly treated groundwater was responsible for many waters borne outbreaks in USA in 2000 and most of them (49\%) caused by Campylobacter, Salmonella, E. coli, and Yersinia. Giardia and Cryptosporidium were also responsible for $18 \%$ of all outbreaks (Craun et al., 2004).

In developing countries evidence of the role of groundwater in causing disease outbreaks is more limited, although there have been numerous studies into the impact of drinking water, sanitation and hygiene on diarrhoeal disease. The limited data on outbreaks specifically linked to groundwater also reflects that improved groundwater sources are generally of good quality.

However, EDHS (2011) from Ethiopia, reported diarrhea prevalence children under age five was highest $(16 \%)$ among children residing in households that drink water from hand pump fitted boreholes sources next from unprotected wells that was 18\% (EDHS,2011). And also, in Kola Tembien typhoid fever, bacterial and protozoan diarrhaoel diseases are the most common disease following malaria (KTDHO, 2013). Although the causative agents of the health problems can vary (with geographical difference, climate, level of sanitation, endemic persistence as well as cultural and socio-economic characteristics of the population) the role of contaminated water sources cannot be underestimating.

The objective of the study was to isolate Klebsiella spp. from hand pumped borehole sources of drinking water and its antimicrobial resistance patterns. 


\section{Materials and Methods}

\subsection{Study Area}

The study was conducted Kola Tembien district which is found central zone Tigray $908 \mathrm{~km}$ far from the capital city of Addis Ababa with the area of 147,000 hectare and a total population of 138,216 (Tigray Livelihood Zone Reports, 2013). The area is situated in $13^{\circ} 39^{\prime} \mathrm{N}, 39^{\circ} 10^{\prime} \mathrm{E}$ and bordered on the North by Werie-Leke, in the East Hawzen and Degua Tembien, in the south Tankua Abergele and in the West Tselemti and Naeder Adet. The administrative center for this district is Abiy Addi.

Ground water (hand dug, hand pump fitted boreholes (fig 5.1)) and spring water are the main sources of drinking water in Kola Tembien rural area. There are 222 shallow hand pump fitted boreholes, 3 deep hand pump fitted boreholes, 193 hand dug and 19-spring water in the area. However, out of the 222-hand pump fitted boreholes only 202 are functional. From the district population, 119, 000 individuals use from the above principal sources of water. But the rest population of the district, use another source like streams, rivers, and lakes (KTDPGCO, 2013).

\subsection{Study design, sample size determination and sampling technique}

A cross-sectional study was conducted from September to November, 2014 in Kola Tembien district, Tigray. Sample size was determining according WHO,2010. The 21 kebelles of the district, which have hand pump fitted boreholes for drinking water sources, 75 of the sources were selected randomly from each kebelles after proportionally allocated to each kebelle.

\subsection{Sample collection, handling and transport}

Twenty-five $\mathrm{ml}$ of drinking water in $30 \mathrm{ml}$ sterile glass bottles and swab samples from the mouth of hand pump fitted boreholes in test tubes containing Cary-Blair medium were collected aseptically by the principal investigator from each source. And sanitary risk assessment sheets or check list was filled during samples collection. Both types of Samples were immediately transported using cold box transport system to Tigray regional laboratory for analysis (WHO, 1997). But in case of delay samples were stored between $2-4^{\circ} \mathrm{C}$ in Abiy-Addi hospital until it was transported to Tigray regional laboratory after collection to avoid the growth or death of microorganisms in the sample but not exceeds 24hrs (USEPA, 2006).

\subsection{Sample processing and Identification}

Biochemical tests were performed on colonies from macConkey agar No.3 (Oxoid.LTD) for final identification of the isolates. Isolates from all culture positive water samples were identified based on the standard cultural and morphological characteristics in couple with indole production, $\mathrm{H}_{2} \mathrm{~S}$ production, gas production, citrate utilization, motility test, lysine decarboxylation, lysine deamination and carbohydrate utilization tests (Vandepitte et al., 2003). 2.5.Antimicrobial susceptibility test

Antimicrobial susceptibility tests isolates were performed on Mueller-Hinton agar (Oxoid.LTD) following the disc diffusion technique. The antimicrobials tested include: Amikacin $(30 \mu \mathrm{g})$, Ampicillin $(10 \mu \mathrm{g})$, Ceftriaxone $(30 \mu \mathrm{g})$, Chloramphenicol, $(30 \mu \mathrm{g})$, Ciprofloxacin $(5 \mu \mathrm{g})$ Gentamicin $(10 \mu \mathrm{g})$ and Tetracycline $(30 \mu \mathrm{g})$. Pure cultures of organisms were enriched in nutrient broth and incubated at $370 \mathrm{C}$ for 3 hrs to a turbidity of 0.5 McFarland standards. The MH agar was inoculated by streaking using sterile cotton swab of each of the cultures. The antibiotic disks were applied using sterile forceps with average distance of $30 \mathrm{~mm}$ from each other in order to prevent overlapping of the zones of inhibition. The agar plates left on the bench for 30 minutes to allow for diffusion of the antibiotics and the plates was incubated inverted at $37^{\circ} \mathrm{C}$ for 24 hours. Results recorded by measuring the zone of inhibition and comparing with the Clinical and Laboratory Standards Institute interpretive performance standard for antimicrobial disk susceptibility testing (CLSI, 2013). The result was recorded as susceptible, intermediate or resistant based on the zone of inhibition measured by ruler. Quality control was performed using Escherichia coli ATCC тм 25922 for Mueller Hinton agar (Oxoid.LTD) and susceptibility patterns of the isolates (CLSI, 2013).

\subsection{Quality control}

Standard operating procedure was followed during sample collection, transportation and analysis. Media were sterilized before samples inoculated and also American type culture collection control strains were used for all culture media and biochemical tests.

\subsection{Ethical consideration}

The study protocol was evaluated and approved by the Research Ethics Review Committee (RERC) of College of Health Sciences, Mekelle University. Moreover, letter of cooperation was written to Tigray regional water resources and energy bureau.

\section{Result and Discussion and conclusion}

Among the total of water sampled from hand pump fitted boreholes, five water $(6.6 \%)$ samples were positive for Klebsiella spp. which are total coliform bacteria that can found in many water environments, and they may multiply to high numbers in waters rich in nutrients (WHO, 2011a). Klebsiella spp. also excreted in the faeces of many healthy humans and animals, and they readily detected in sewage-polluted water (WHO, 2006). In this study, Klebsiella spp. were isolated from $6.6 \%$ of the total water sampled. from drinking water sample. However, studies in Nigeria by Aina et al. (2012) found that $27.7 \%$ of water samples were positive for Klebsiella spp. and also a 
study conducted by Bello et al. (2013b) found $66.6 \%$ of total water sampled were positive for Klebsiella spp. these both studies showed that high percentage of isolated Klebsiella spp.

Klebsiella spp. isolated from water samples were sensitive to all antibiotics tested in our study except Ampicillin and Tetracycline. Among the five isolated of Klebsiella spp. from water sampled, 2 of them were resistance to Ampicillin and one was resistance to Tetracycline. This finding was agreed with study conducted by Bello et al. (2013b) and Odeyemi et al. (2011). Since community acquired antibacterial resistance of Klebsiella spp. has a great public health importance, researchers should give attention like hospital acquired one.

\section{Conclusion}

Even though, underground water is believed to be the purest form of water, it may contaminate by microbial pathogens. The isolates of Klebsiella spp. from this study suggested the possible contamination of underground water. And also, this indicates, assessment of drinking water only by testing total and faecal coliforms is not enough.

Besides, this study showed that there were Klebsiella spp. which importance, researchers should give attention like hospital acquired one. And also, possible sources of contamination and species identification need further study.

\section{Abbreviations}

ATCC-American Type Culture Collection

CFU- Colony Forming Unit

CLSI-Clinical and Laboratory Standards Institute

KTDPGCO-KolaTembien District Public and Government Communication Office

KTDWRO-Kola Tembien District Water Resources Office

MDG-Millennium Development Goals

MHA- Mueller-Hinton agar (MHA)

MF-Membrane Filteration

UNICEF-United Nations Children's Fund

WHO-World Health Organization

\section{Competing interests}

The author declares there was no conflicts of interest.

\section{Acknowledgements}

The author gratefully acknowledges the support of Kola Tembien district water and energy bureau for their support during the sample collection. The authors would like to acknowledge staffs of Tigray Regional Laboratory and Ayder referral Hospital microbiology Laboratory to providing facilities.

\section{Author details}

Tigray Health Research Institute, Mekelle, Tigray, Ethiopia P-O-Box-07

\section{References}

Aina D, Olawuyi O, Coker O, Ojelabi D, Alatise F (2012). Bacteriological analysis of hand pump fitted borehole water from different towns in Ogun State, Nigeria. AJMR. 6(10); 2462-2468.

Bagley S T. (1985). Habitat association of Klebsiella species. Infect Control. 1985; 6:52-58.

Bello OO, Osho A, Bello TK (2013b). Microbial quality and antibiotic susceptibility profiles of bacterial isolates from hand pump fitted borehole water used by some schools in Ijebu-Ode, Southwestern Nigeria. SAJB. 1(1); 4-13.

Central Statistical Agency [Ethiopia] and ICF International. 2012. Ethiopia Demographic and Health Survey 2011. Addis Ababa, Ethiopia and Calverton,Maryland, USA: Central Statistical Agency and ICF International.

Craun GF, Calderon RL, Craun MF (2004). Waterborne Outbreaks Caused by Zoonotic Pathogens in the United States. Available at: (http://www.who.int/water_sanitation_health/diseases/zoonosesintro.pdf)

Kola Tembien District Health Office (2013). Annual report $201 \overline{3}$.

Kola Tembien District Public and Government Communication Office (2013). Annual Book 2013.

Odeyemi AD., Fagbohun EM., and Oluwakemi Akindolap OL. (2011). The bacteriological and physico chemical studies on Olumirin waterfall erinijesha, osun state. Nigeria.1:83-97.

Pandey PK, Kass PH, Soupir ML, Biswas S, Singh VP (2014). Contamination of water resources by pathogenic. Appl. Microbiol. Biotechnol. 4:51.

Prüss, A. and Havelaar, A. (2001). The Global Burden of Disease: Study and Applications in Water, Sanitation and Hygiene. In: Fewtrell, L. and Bartram, J., Eds., Water Quality: Guidelines, Standards and Health, Risk Assessment and Management for Water-Related Infectious Disease, IWA Publishing, London, 43-59.

USEPA (2006). Distribution system indicators of drinking water quality. Washington, DC: EPA. Available at :( www.epa.gov/ogwdw/disinfection/tcr//issuepaper tcr_indicators.pdf).

Vandepitte J, Verhaegen J, Engbaek K, Rohner P, Piot P, Heuck CC (2003). Basic laboratory procedures in clinical 
bacteriology.2nd ed. World Health Organization Geneva, Switzerland.42-59.

WHO (1997). Guidelines for drinking-water quality. Surveillanceand control of community supplies.2nd end. World Health Organization, Geneva. Available at: (www.who.int/water_sanitation_health/dwq/gdwqvol32ed.pdf).

WHO (2004b). Rolling Revision of the WHO Guidelines for Drinking-Water Quality. World Health Organization, Geneva. Available at: (www.who.int/water...health /.../nutintakes.pdf)

WHO (2013). Water Quality and Health Strategy 2013-2020. World Health Organization, Geneva. Available at: (www.who.int/water_sanitation_health/dwq/). 